\title{
A system consists of lifted steel tank and four assembly supports with variable assembly conditions
}

https://doi.org/10.2478/sgem-2018-0026

received August 17, 2018; accepted October 11, 2018.

\begin{abstract}
In the method of steel tank erection, consisting in assembling the roof and the next courses (segments) of the shell at the ground level, starting from the top one (the so-called hydraulic jacking-up method), the assembled part of the tank is lifted using assembly supports (towers, trestles), hydraulic jacks and ropes. Supports are located inside or outside the tank, and their bases are usually not anchored. During the assembly work, numerous contaminations can appear under the bases of the supports; therefore, boundary conditions of the system consisting of the elevated tank and assembly supports may change, influencing the field of displacements and stresses in the elements of this system. This article presents the results of numerical tests of an exemplary mounted tank - mounting support system - at various possible coefficients of friction between the bases of the supports and the ground. The influence of the support conditions on the effort of the essential elements of the system was assessed. Calculation difficulty was noted to determine the directions of horizontal responses of the supports. It was assumed that these directions did not change after exceeding the values of the friction forces. The analysed tank collapsed during its erection.
\end{abstract}

Keywords: Tank; method of erection; hydraulic jacking; disaster.

\section{Introduction}

A cylindrical steel tank for liquid with a vertical axis and with the following parameters, $V=1,200 \mathrm{~m}^{3}, H=$

\footnotetext{
*Corresponding author: Grzegorz Gremza, Faculty of Civil Engineering, Silesian University of Technology, Gliwice, Akademicka 5, Poland, E-mail: grzegorz.gremza@polsl.pl

Jan Zamorowski: University of Bielsko-Biała, Bielsko-Biała, Poland
}

$20 \mathrm{~m}, m=38.85 \mathrm{t}$, was mounted. The shell of the tank consisted of 10 shell courses (segments) with respective thicknesses of $5 \mathrm{~mm}$ - courses from 1 to $4,6 \mathrm{~mm}$ (courses 5-6), $7 \mathrm{~mm}$ (courses 7-8) and $8 \mathrm{~mm}$ (courses 9-10). During the assembly of each segment, the shell of the tank was stiffened on fragments of its lower edge using bowed (cambered) channels about 3.0-m long, to which connectors were welded. To mount the tank, four steel towers (trestles) with the height of $4.5 \mathrm{~m}$, characterised by a working stroke of $2.6 \mathrm{~m}$, were used (Figure 1). The tower consisted of two-chord internal (i.e. at the tank side) branches arranged from the HEA sections and two-chord external branches made from the $\mathrm{C}$ sections. Branches were linked together by the use of lacings placed in the chord planes. Chords of the internal branch of the tower were connected using a base plate and two beams. One of these beams was located at about two-thirds of the tower height, and the second one made a connection of chords at their top ends. In addition, these chords at about one-third of the height were linked to each other by the anchoring element for ropes. By the use of these ropes and the piston jack, a lifting chair (carriage) was moved. Between the internal chord branches, a hydraulic jack with a lifting capacity of $150 \mathrm{kN}$ and a system of rolls and ropes with the carriage were located. The towers were arranged on a reinforced concrete plate without any anchorage. The horizontal base plate had dimensions of $1,100 \mathrm{~mm}{ }^{\prime} 1,100 \mathrm{~mm}^{\prime} 14 \mathrm{~mm}$. The layout of a tower is shown in Figure 1.

To each carriage, two connectors were welded, one on each side (Figure 1). These connectors were welded on the other side to the bowed channel with a depth of $240 \mathrm{~mm}$ and length of $l=3.0 \mathrm{~m}$, which were temporarily connected to the tank shell using four elements (Figure 2). Two of these elements were placed at both ends of the bowed channel and welded either to its flange or the tank shell. Remaining two ones, located in the middle of the channel, were welded to both its flanges - the upper and the lower - and to the tank shell. The connectors with different cross sections and length were used to 


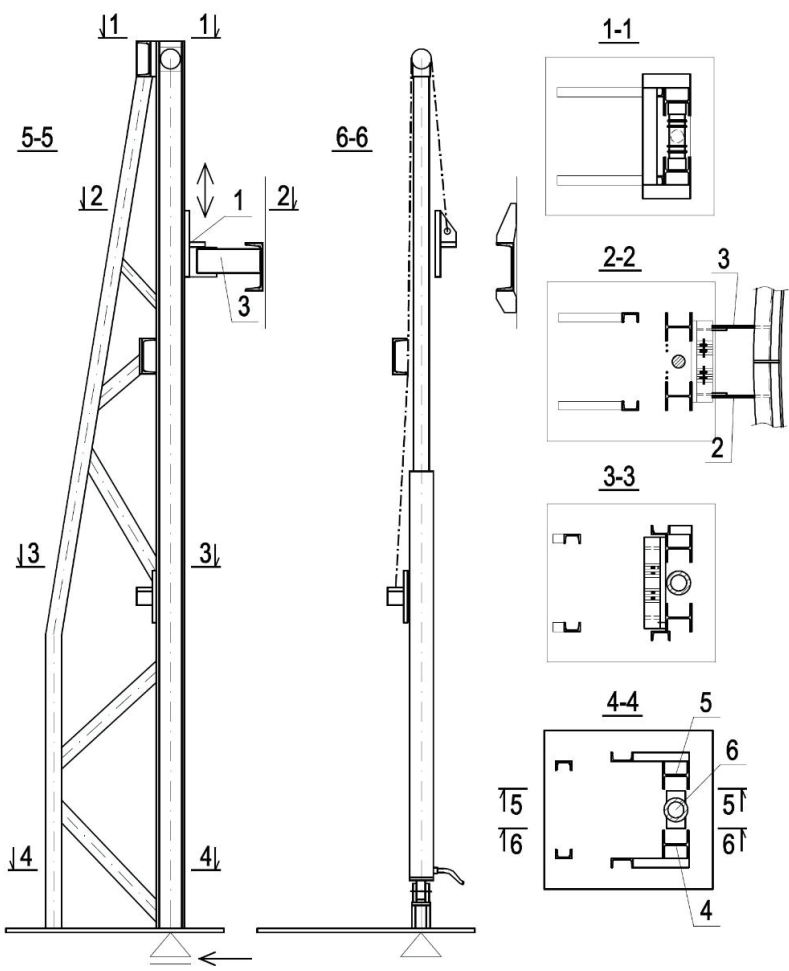

Figure 1: Layout of a tower used for tank assembly: 1 , carriage (lifting chair); 2, connector A; 3, connector B; 4, chord A; 5, chord B; 6, jack join the carriages to the channels welded to the tank. In the specification, there was no information on either the dimensions of these elements or dimensions of welds, which should connect these connectors to carriages and channels. These elements, as well as channels, were executed and fixed to the tower and to the tank by the experience acquired during the assembly of other tanks. The solution described earlier was a specific variant of the erection methods, as discussed, for example, in Ref. [1]. Lifting methods are quite often used for erection $[2,3,4]$ as well as for repairing many tanks [5].

The tank was built by the use of a lifting (jacking-up) method with mounting sheet by sheet the lower shell course $[6,7]$. The previously assembled part of the tank was lifted up by the use of carriages that were vertically moved along the tower by jacks, simultaneously activated on all towers. After lifting the tanks to the level slightly higher than $2 \mathrm{~m}$, the lower shell course was formed, and the tank was lowered sequentially by the use of each jack, leaving a gap allowing proper execution of a weld between the lower shell course and the previously assembled part of the tank (Figure 2). During the lowering of the tank, in every $50 \mathrm{~mm}$, the opening of this gap was controlled and

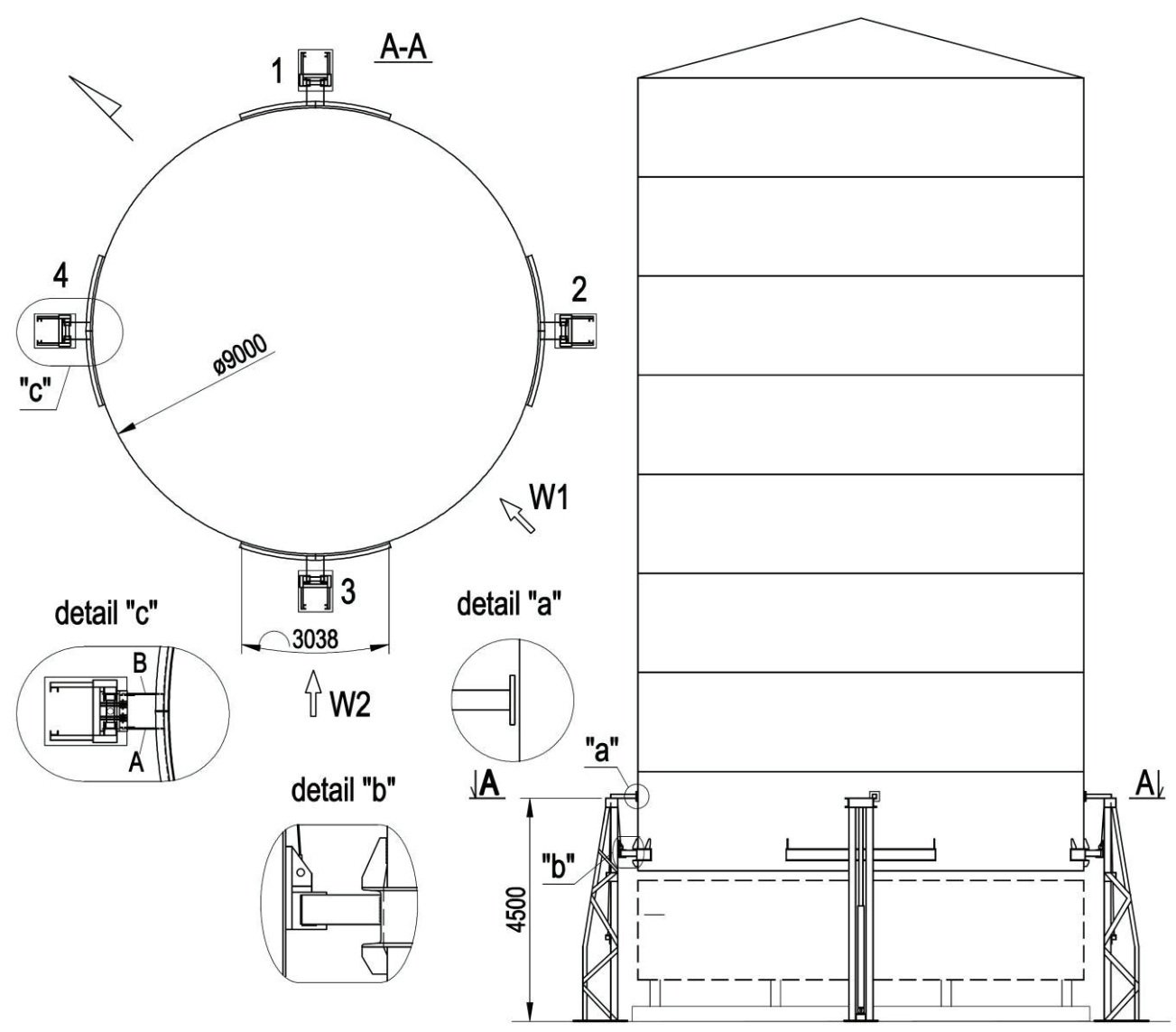

Figure 2: Scheme of the tank assembly. 
adjusted if necessary. After the weld execution between a lower shell course and previously assembled part of the tank, channels were cut from the shell, and, if necessary, connectors were cut from the channels. Next, channels were welded at the bottom of the next shell course, and the whole cycle was repeated.

In opposite to the design solution, the additional cantilevers were welded to the tops of some towers, on which the lifted or lowered tank could move slipping (Figure 2, detail a). Therefore, it can be concluded that, during lifting or lowering the tank, the tower tilted in the tank direction and these cantilevers were to protect the towers against the loss of stability.

A disaster occurred when the tank, during the assembly of the ninth layer, was lowered. The gap at one of the jacks was corrected, and then the tank was lowered. When about $2 \mathrm{~cm}$ was lacking to complete the operation, it was observed that the tank suddenly tilted, then one of the connectors broke, and the tank fell down to the side. The condition of the towers and connectors after the disaster, determined from the photographs of the place of disaster, was as follows:

a) The tower from the north-east side broke away from the tank (Figure 2, tower no. 1). Based on the testimony of one of the witnesses, who were standing by this tower at the time of the disaster, it can be concluded that the connectors broke away from the channels welded to the tank.

b) In the case of the tower from the north-west side (tower no. 4), one of the connectors disconnected from the tower and the other from the tank.

c) After the catastrophe, the tower from the southwestern side (no. 3) was still connected to the tank.

d) In the tower from the south-east side (no. 2), one of the connectors was detached from the tower during the disaster, and the second one was most probably cut-off from the tank after the disaster. The vertical weld joining the detached connector to the carriage of the tower was of poor quality, and only the horizontal weld was of standard value (Figure 3).

\section{Computational models}

The computational model of a system tank - four towers made in the computer programme Robot - is shown in Figure 4.

Loads from the assembled tank were transferred to the carriages of the towers, which in turn transmitted them to the hydraulic jack and internal chords of the tower. Due to the lack of anchorage of the towers in a base

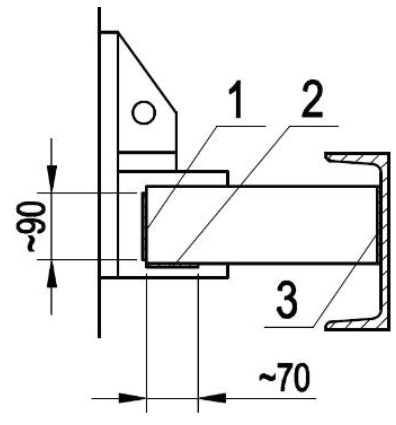

Figure 3: Details of connector welding: 1 and 2, fillet welds in the broken lap joint (1, low-quality weld; 2 , proper quality weld); 3 , double fillet weld

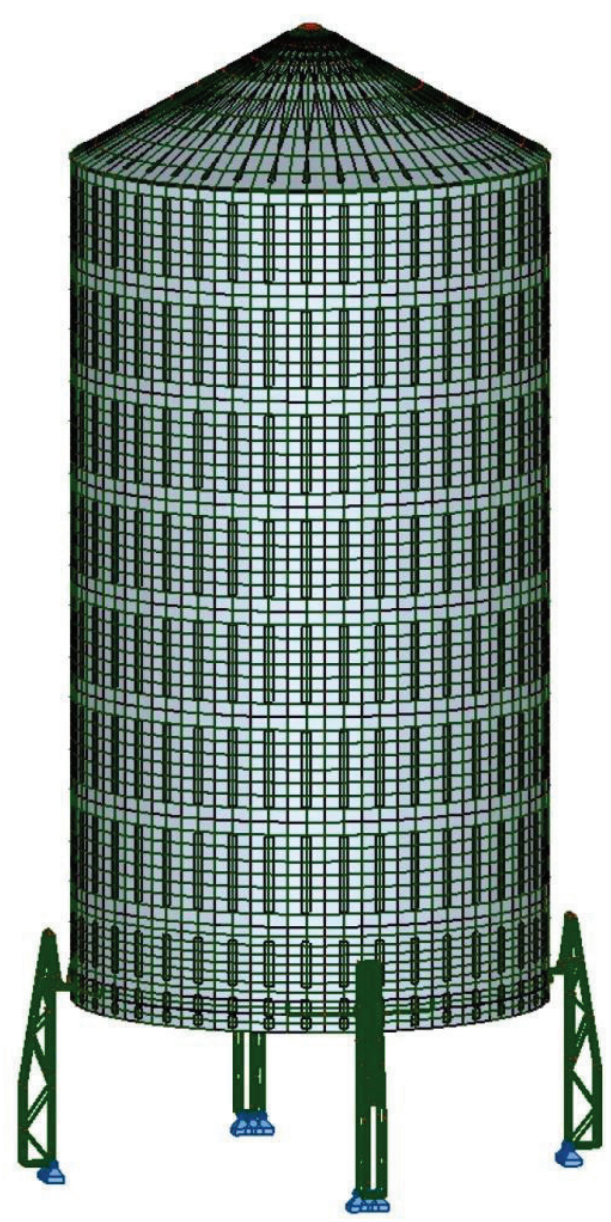

Figure 4: Model of a system tank-four towers.

concrete plate, it was difficult to identify their restraints at the support.

Each of the towers could be potentially subjected to a horizontal displacement, either rotation to the vertical axis or rotation to the horizontal axis. Due to the very low bending stiffness of the horizontal base plate of the tower 
as well as the fact that the tower chords and jacks were compressed with significantly different values of axial forces, independent constraints for these chords and jacks were adopted. In the horizontal plane, the supported nodes were connected by a system of horizontal bars replacing the influence of the horizontal plate of the tower base.

Vertical restraints under internal chords of the towers were introduced in the computational model. Due to the lack of anchoring of the tower in the substructure, vertical restraints for the outer chords of the towers were not used. Horizontal restraints with radial and tangential direction, placed under inner, compressed chords and jacks, could only result from friction forces, with maximum, resultant horizontal reactions for ith restraint (1):

$$
H_{i, \max }=\mu V_{i}
$$

where $\mu$ is the friction coefficient of the tower bases on the reinforced concrete slab, depending on the state of the surface contamination and vertical action of the tower chord or the jack, $V_{i}$ is the vertical reaction.

Friction coefficient could take values in the range from 0.0 on a heavily contaminated surface between the horizontal base plate of the tower and the reinforced concrete foundation slab up to 0.3 for a clean joint. The condition of the contact surface at the time of the disaster was not known. It was assumed in the calculation that the direction of the horizontal reactions of the chords of the inner wall of the tower does not change after exceeding the value of friction forces.

Considering the abovementioned assumptions, the horizontal support restraints of the tower chords were introduced into the calculation model for $H_{i} \leq H_{i, \max }$, where $H_{i}=\left(H_{i, r}^{2}+H_{i, \tau}^{2}\right)^{0.5}$ and $H_{i, r}, H_{i, \tau}$ are the horizontal radial and tangential reactions. After crossing this limit, instead of restraints earlier, horizontal actions with a value $H_{i, \max }$ and the primary direction were introduced into the model. It was assumed that the kinetic friction coefficient is equal to half of the value of the static friction coefficient.

Independent modelling of the chord and jack support in the calculation model allowed for simple recognition of the influence of twisting the towers, which may have appeared due to their two-way bending resulting from wind action. In such a case, the values of friction forces under one of the tower chords could be exceeded.

The calculations were made for two variants of tower construction: a) towers with cantilevers (Figure 2, detail a) and $b$ ) towers without cantilevers. In both variants, the inside distance between the tower and the tank equal to $410 \mathrm{~mm}$ was assumed.
In the calculations, the own weight of the assembled tank $G=258.9 \mathrm{kN}$ and the wind load for the wind speed $v=4.0 \mathrm{~m} / \mathrm{s}$, which occurred during the disaster, were included. These calculations were made by the standard procedure [8].

\section{Results of computations}

The calculations were made as iterative. In the first step, pinned supports under columns (chords) of internal branches (see chord A and chord B in Figure 1) as well as under jacks were introduced. Assuming the lack of anchorage of the tower in the base level, the values of actions ( $\mathrm{kN}$ and $\mathrm{kNm})$ as summarized in Table 1 were obtained.

Columns 8, 9 and 10 of the table list the values of relations of the actions - horizontal $H$ to vertical $V$. For restraints under the jacks, these values are minimal, indicating that during lifting (or lowering) of the tank the towers did not displace horizontally. In turn, large values of $H / V$ ratios for the chords of the inner wall of the towers indicate that the towers could rotate concerning the vertical restraint under the jack.

In the next steps, instead of horizontal restraints under the chords of the tower, friction forces were introduced. The value of the static friction coefficient $\mu=0.3$ and the kinetic friction at $\mu=0.15$ were taken into account. For such values of horizontal actions, internal forces in connectors, as well as displacements and forces in the tank shell, were determined. Exemplary values of internal forces in cross sections of the connector for the wind direction W2 are summarized in Table 2. For comparative purposes, values as mentioned earlier were supplemented with values of the forces obtained for $\mu=\infty$, assuming hinged supports under the internal chords of the towers.

Results obtained from the calculation indicate a small effect of support condition of the tower without any additional cantilever on the values of internal forces in the connectors. The maximum differences in the significant values of bending moments (which determined the design of elements) reached $6.7 \%$ in the cross section of the connector at the tank and in the cross section at the tower only $1.2 \%$. More significant differences occurred in the values of axial forces, approximately $40 \%$, with a maximum value of $N_{\max }=5.12 \mathrm{kN}$. Similar results were obtained for towers with additional cantilevers.

The dimensions of welds in the connections of the connector with the bowed channel and the tower carriage as well as the load-bearing capacity of these welds were 
Table 1: Actions of the towers $(\mathrm{kN})$ based on pinned supports.

\begin{tabular}{|c|c|c|c|c|c|c|c|c|c|}
\hline \multirow[t]{2}{*}{ No. of towers } & \multicolumn{3}{|c|}{ Vertical action $(V)$} & \multicolumn{3}{|c|}{ Resultant horizontal action $(H)$} & \multicolumn{3}{|c|}{ Ratio of actions $(H / V)$} \\
\hline & Chord $A$ & Jack & Chord $B$ & Chord $A$ & Jack & Chord $B$ & Chord $A$ & Jack & Chord $B$ \\
\hline 1 & 2 & 3 & 4 & 5 & 6 & 7 & 8 & 9 & 10 \\
\hline \multicolumn{10}{|c|}{ Wind W1 - towers without cantilevers } \\
\hline 3,2 & $-\star$ & 60.83 & 10.40 & $-*$ & 4.013 & 3.423 & $-*$ & 0.066 & 0.329 \\
\hline 4,1 & 5.45 & 62.79 & 4.57 & 3.868 & 0.014 & 3.629 & 0.710 & 0.000 & 0.794 \\
\hline \multicolumn{10}{|c|}{ Wind W1 - cantilevers on the chord A in every towers } \\
\hline 1 & 5.76 & 62.57 & 4.69 & 2.554 & 0.014 & 3.359 & 0.443 & 0.000 & 0.716 \\
\hline 2 & 11.38 & 59.84 & $-*$ & 2.768 & 3.147 & $-*$ & 0.243 & 0.053 & $-{ }^{*}$ \\
\hline 3 & $-{ }^{*}$ & 62.15 & 9.30 & $-{ }^{*}$ & 2.374 & 3.539 & $-*$ & 0.038 & 0.380 \\
\hline 4 & 6.08 & 62.37 & 4.36 & 2.885 & 0.000 & 3.007 & 0.475 & 0.000 & 0.690 \\
\hline \multicolumn{10}{|c|}{ Wind W2 - towers without cantilevers } \\
\hline 3 & 4.80 & 57.51 & 4.80 & 3.291 & 0.010 & 3.291 & 0.686 & 0.000 & 0.686 \\
\hline 4, 2 & 2.83 & 65.46 & 7.38 & 4.846 & 0.022 & 3.152 & 1.173 & 0.000 & 0.427 \\
\hline 1 & 4.87 & 59.83 & 4.87 & 3.551 & 0.010 & 3.551 & 0.729 & 0.000 & 0.729 \\
\hline \multicolumn{10}{|c|}{ Wind W2 - cantilevers on the chord A in every towers } \\
\hline 1 & 4.71 & 61.79 & 5.66 & 2.761 & 0.010 & 3.121 & 0.586 & 0.000 & 0.551 \\
\hline 2 & 6.01 & 62.99 & 4.40 & 2.400 & 0.000 & 3.833 & 0.399 & 0.000 & 0.871 \\
\hline 3 & 4.45 & 59.25 & 5.83 & 2.311 & 0.010 & 2.700 & 0.519 & 0.000 & 0.463 \\
\hline 4 & 3.52 & 62.97 & 6.89 & 3.464 & 0.020 & 2.750 & 0.984 & 0.000 & 0.399 \\
\hline
\end{tabular}

*Lifted support, removed from the model.

Table 2: Internal forces in connectors for the towers without cantilevers: wind W2.

\begin{tabular}{|c|c|c|c|c|c|c|c|c|c|c|c|c|}
\hline \multirow[t]{5}{*}{$\bar{\mu}$} & \multirow{2}{*}{\multicolumn{3}{|c|}{$\begin{array}{l}\text { Tower no. } 3 \\
\text { Connector } A \text { and } B\end{array}$}} & \multicolumn{6}{|c|}{ Tower no. 4} & \multicolumn{3}{|c|}{ Tower no. 1} \\
\hline & & & & \multicolumn{3}{|c|}{ Connector $\boldsymbol{A}$} & \multicolumn{3}{|c|}{ Connector $B$} & \multicolumn{3}{|c|}{ Connector $A$ and $B$} \\
\hline & $M$ & $\boldsymbol{V}$ & $\boldsymbol{N}$ & $M$ & $\boldsymbol{V}$ & $\boldsymbol{N}$ & $M$ & $\boldsymbol{V}$ & $\boldsymbol{N}$ & $M$ & $\boldsymbol{V}$ & $\boldsymbol{N}$ \\
\hline & $\mathrm{kNm}$ & kN & kN & kNm & kN & kN & $\mathrm{kNm}$ & $\mathbf{k N}$ & $\mathbf{k N}$ & kNm & kN & $\mathbf{k N}$ \\
\hline & 1 & 2 & 3 & 4 & 5 & 6 & 7 & 8 & 9 & 10 & 11 & 12 \\
\hline & \multicolumn{12}{|c|}{ In the cross section at the side of the tank } \\
\hline 0 & 2.061 & -30.0 & 3.27 & 1.504 & -34.9 & 4.24 & 1.496 & -33.7 & 3.76 & 1.539 & -31.3 & 3.58 \\
\hline 0.15 & 2.088 & -30.0 & 3.26 & 1.502 & -34.8 & 3.92 & 1.497 & -33.8 & 4.08 & 1.541 & -31.3 & 3.59 \\
\hline 0.3 & 2.113 & -30.0 & 3.25 & 1.499 & -34.7 & 3.63 & 1.498 & -33.9 & 4.37 & 1.514 & -31.3 & 3.60 \\
\hline \multirow[t]{2}{*}{$\infty$} & 1.981 & -30.0 & 3.29 & 1.505 & -35.1 & 5.12 & 1.486 & -33.5 & 2.89 & 1.641 & -31.3 & 3.56 \\
\hline & \multicolumn{12}{|c|}{ In the cross section at the side of the carriage } \\
\hline 0 & -6.526 & -30.0 & 3.27 & -8.478 & -34.9 & 4.24 & -8.149 & -33.7 & 3.76 & -7.376 & -31.3 & 3.58 \\
\hline 0.15 & -6.499 & -30.0 & 3.26 & -8.457 & -34.8 & 3.92 & -8.171 & -33.8 & 4.08 & -7.405 & -31.3 & 3.59 \\
\hline 0.3 & -6.474 & -30.0 & 3.25 & -8.439 & -34.7 & 3.63 & -8.191 & -33.9 & 4.37 & -7.432 & -31.3 & 3.60 \\
\hline$\infty$ & -6.608 & -30.0 & 3.29 & -8.540 & -35.1 & 5.12 & -8.095 & -33.5 & 2.89 & -7.301 & -31.3 & 3.56 \\
\hline
\end{tabular}

estimated. As a result, it was found that the load-bearing capacity of welds in connections with the channel was sufficient, and the load-bearing capacity of connections with the carriage in some cases could be even several times too small, which was the cause of the disaster.
Table 3 summarizes the radial displacement of the tank shell at the location of its connection to the channel in the plane of symmetry between connectors. The most significant radial displacement of the shell was obtained under the connector of the windward tower (no. 3), and its value was $4.54 \mathrm{~cm}$, with a coefficient of friction $\mu=0.30$. 
Table 3: Radial displacements of the shell in a connection point for the wind W2.

\begin{tabular}{lllllllll}
\hline $\boldsymbol{\mu}$ & \multicolumn{9}{l}{ Towers without cantilevers } & \multicolumn{9}{l}{ Towers with cantilevers } \\
& No. 3 & No. 4 & No. 1 & No. 2 & No. 3 & No. 4 & No. 1 & No. 2 \\
\hline- & $\mathrm{cm}$ & $\mathrm{cm}$ & $\mathrm{cm}$ & $\mathrm{cm}$ & $\mathrm{cm}$ & $\mathrm{cm}$ & $\mathrm{Cm}$ & $\mathrm{cm}$ \\
0 & 4.40 & 2.64 & 2.96 & 2.64 & 2.85 & 2.18 & 2.29 & 2.19 \\
0.15 & 4.48 & 2.64 & 2.89 & 2.64 & 2.86 & 2.18 & 2.28 & 2.20 \\
0.3 & 4.54 & 2.64 & 2.82 & 2.64 & 2.87 & 2.18 & 2.27 & 2.20 \\
$\infty$ & 4.20 & 2.64 & 3.16 & 2.64 & 2.81 & 2.18 & 2.33 & 2.20 \\
\hline
\end{tabular}

Table 4: Resultant normal stress in the shell in the connection points for the wind W2.

\begin{tabular}{lllllllll}
\hline$\mu$ & \multicolumn{2}{l}{ Towers without cantilevers } & & \multicolumn{2}{l}{ Towers with cantilevers } \\
& No. 3 & No. 4 & No. 1 & No. 2 & No. 3 & No. 4 & No. 1 & No. 2 \\
- & $\mathrm{MPa}$ & $\mathrm{MPa}$ & $\mathrm{MPa}$ & $\mathrm{MPa}$ & $\mathrm{MPa}$ & $\mathrm{MPa}$ & $\mathrm{MPa}$ & $\mathrm{MPa}$ \\
\hline 0 & $209.9 / 178.7$ & $202.3 / 179.2$ & $191.1 / 168.7$ & $202.4 / 179.2$ & $141.3 / 169.0$ & $149.8 / 151.5$ & $144.9 / 149.5$ & $147.8 / 153.0$ \\
0.15 & $211.0 / 179.6$ & $205.5 / 179.3$ & $190.0 / 167.8$ & $205.6 / 179.2$ & $142.3 / 169.4$ & $151.7 / 151.4$ & $145.5 / 149.5$ & $147.2 / 152.9$ \\
0.3 & $212.1 / 180.3$ & $208.5 / 179.3$ & $188.9 / 167.0$ & $208.5 / 179.3$ & $143.5 / 169.8$ & $153.6 / 151.4$ & $146.3 / 149.5$ & $146.9 / 152.9$ \\
$\infty$ & $206.6 / 176.3$ & $207.9 / 178.9$ & $194.2 / 170.9$ & $207.9 / 178.9$ & $143.5 / 165.9$ & $146.3 / 151.5$ & $146.7 / 149.3$ & $155.1 / 152.7$ \\
\hline
\end{tabular}

*The first of the values in cells refers to the stress in the area of the connections at the ends of the channel and the second value pertains to the stress in the area of the connection at half of the length of this channel (see figure 2).

The influence of the coefficient of friction on the value of this displacement reached $6.8 \%$. Additional cantilevers mounted on the top of the towers caused a decrease in the value of radial displacements at the connector location.

Table 4 summarizes the values of reduced stress in the location under the connector. These stresses were lower than the design strength of the steel of the tank shell. The spread of values of these stresses depending on the coefficient of friction was also small and reached about $3.1 \%$.

\section{Conclusion}

The paper analyzes the influence of boundary conditions of the assembly supports of the tank on the state of internal forces in connectors between these supports and tank as well as the state of displacements and stresses in the tank's shell at the places where it is connected to these connectors. It was assumed that the tank's assembly supports were freely placed on hardened (reinforced concrete) ground and could move on it after exceeding friction forces as well as rotate around their own axis.

The obtained results indicate small influence of support conditions of the assembly supports on the values of the internal forces in connectors as well as on its effort. The maximum differences in the significant values of bending moments in connectors (which determined the stress value) in their cross sections at the tank side reached $7 \%$, and in the cross sections at the support side only $1.2 \%$. Bigger differences were found in the values of axial forces. They were about $40 \%$, but their impact on the total effort of the connector was negligible.

The influence of the coefficient of friction on the radial displacements of the tower's shell at the place of its connection with the supports was also of little importance. It reached $7 \%$, with radial displacements of the shell exceeding a bit over $5 \mathrm{~cm}$. The abovementioned result indicates the possibility of a fairly large radial deformation of the tank, which may be the reason for the assembly imperfections of the shell. These deformations can be significantly reduced by fixing the assembly supports in the ground. Such restraint would also be advantageous due to the possibility of additional horizontal forces occurring, e.g. due to accidentally hitting the tower with a steel element or excessive deflection of the assembled part of the tank.

A slightly greater influence of support conditions of assembly towers was found in the case of normal resultant stresses in the tank's shell at the places, where it was connected to the supports. Dispersion of values of these stresses depending on the coefficient of friction was also 
small and reached about 10\%. These stresses were lower than the design strength of the steel of the tank's shell.

As a result of the performed analysis, it was also found that the direct cause of the disaster of the analysed tank was detachment of one of the connectors from the assembly tower, due to exceeding the load capacity of the welds connecting this connector to the carriage (lifting chair) of the tower. The described situation was caused by deficiencies in the scope of the execution specification of the tank [9].

\section{References}

[1] Supernak, E. (2006). Comparison of assembly methods for steel vertical cylindrical tanks [Porównanie metod montażu stalowych, pionowych zbiorników walcowych], Magazyn Ex, 28(4), 40-52 (in Polish).

[2] Pullarcot, S. (2015). Above Ground Storage Tanks: Practical Guide to Construction, Inspection, and Testing. CRC Press Taylor \& Francis Group, Boca Raton.

[3] Ziótko, J. (1986). Zbiorniki metalowe na ciecze i gazy [Metal Tanks for Liquids and Gases]. Arkady, Warszawa (in Polish).

[4] Ziółko, J., Orlik, G. (1980). Montaż konstrukcji stalowych [Assembly of Steel Structures]. Arkady, Warszawa (in Polish).

[5] American Petroleum Institute. (2014). API Standard 653: Tank Inspection, Repair, Alteration, and Reconstruction, 5th edn. API Publishing Services, Washington, D.C.

[6] Yan, N.B., Han, T.Z., Wilton, T., Rui, T. Y. (2016). Analysis of Jacking-up Method for Tank Erection. Singapore Polytechnic, Singapore.

[7] Kuan, S. I. (2009). Design, Construction and Operation of the Floating Roof Tank. University of Southern Queensland. (Course ENG 4111 and ENG 4112 Research Project).

[8] Polski Komitet Normalizacyjny (2009). Polish Standard PN-EN 1993-4-2: 2009: Eurocode 3 - Design of steel structures - Part 4-2: Tanks.

[9] Polski Komitet Normalizacyjny (2012). Polish Standard PN-EN 1090-2+A1: 2012: Execution of steel structures and aluminium structures - Part 2: Technical requirements for steel structures. 